\title{
Meaningful Inclusion of Consumers in Research and Service Delivery
}

\author{
van Draanen, Jenna; Jeyaratnam, Jeyagobi; O'Campo, Patricia; \\ Hwang, Stephen; Harriott, Dawnmarie; Koo, Michael; \\ Stergiopoulos, Vicky
}

Version Post-Print/Accepted Manuscript

Citation van Draanen, Jenna; Jeyaratnam, Jeyagobi; O'Campo, Patricia; Hwang, (published version) Stephen; Harriott, Dawnmarie; Koo, Michael; Stergiopoulos, Vicky. (2013). Meaningful inclusion of consumers in research and service delivery. Psychiatric Rehabilitation Journal, Vol 36(3), 180-186, http://dx.doi.org/10.1037/prj0000014.

Publisher's Statement This article may not exactly replicate the authoritative document published in the APA journal. It is not the copy of record.

PsycINFO Database Record (c) 2017 APA. All rights reserved.

Always cite the published version, so the author(s) will receive recognition through services that track citation counts, e.g. Scopus. If you need to cite the page number of the TSpace version (original manuscript or accepted manuscript) because you cannot access the published version, then cite the TSpace version in addition to the published version using the permanent URI (handle) found on the record page. 
Running head: INCLUDING CONSUMERS IN RESEARCH AND SERVICE DELIVERY

Meaningful Inclusion of Consumers in Research and Service Delivery

Author note

This research was supported through funding from the Mental Health Commission of Canada 


\begin{abstract}
Objective. Although participatory methods have become increasingly popular, people with lived experience of mental illness and homelessness have been historically excluded from service planning and research. To better plan for meaningful inclusion of consumers, this study examines lessons learned from the People with Lived Experience Caucus in the Toronto Site of the At Home/Chez Soi Research Demonstration Project on Homelessness and Mental Health. Methods. The inclusion of the People with Lived Experience Caucus was evaluated using qualitative methods and multiple data sources, including review of 42 documents, 11 individual interviews, and 3 focus groups. Caucus members were included in the study team. Transcripts were analyzed using grounded theory methodology. Results. Findings revealed a complex story of Caucus engagement: facing time constraints and given little direction, the Caucus developed through a tumultuous process related to both internal and external barriers to meaningful inclusion. Despite the challenges, the Caucus contributed meaningfully to various aspects of the research demonstration project. Conclusions and Implications for Practice. It is possible to successfully integrate psychiatric consumers with experience of homelessness in many aspects of research and service planning. Suggestions for future initiatives hoping to engage consumers include: early involvement, purposeful selection of members, clear communication of roles and responsibilities, a consumer coordinating group and space for critical dialog throughout the process. Lessons learned can inform the inclusion of consumers in similar endeavors in other jurisdictions.
\end{abstract}

Key words: consumer research; people with lived experience; program evaluation; mental illness 


\section{Introduction}

The perspectives of consumers of mental health services have historically been left out of psychiatric literature (Cohen, 2005). Given that such perspectives can offer valuable input on areas for improvement in service delivery (Cohen, 2005), there has been increasing recognition of the need to facilitate inclusion of people with mental illness in planning and evaluating services directed at this population. (Carling, 1995; Nelson, Lord \& Ochocka, 2001; Trainor, Pomeroy \& Pape, 1999; Ochocka, Janzen \& Nelson, 2002).

Calls for participation of service recipients, some of whom identify as "consumer survivors" and others who identify as "consumers" or "people with lived experience" (PWLE) have noted that participation in decision-making, research, and evaluation is a potential means for empowering this disadvantaged group (Lord \& Dufort, 1996). Given the disparity of power between consumers and health professionals, (Constantino \& Nelson, 1995; Lord \& Dufort, 1996; Nelson et al. 2001) consumers and researchers and the desire to address these power dynamics through genuine partnerships, previous research has focused on the potential benefits of involving consumers and the hindering and facilitating factors involved in forming partnerships with consumers (Church, 1996; Trainor et al.,1999; Lord \& Church, 1998; Nelson, Lord, \& Ochocka, 2001).

The literature suggests two primary strategies for developing more equitable relationships between professionals and consumers, including: 1) educating professionals about interactions with consumers (Constantino \& Nelson, 1995; Ochocka, Nelson \& Lord, 1999) and; 2) increasing participation of consumers in decision making (Church, 1992; Trainor Pomeroy \& Pape, 1999). 
The importance of involving consumers in research has also been recognized, with several benefits described by Happell and Roper (2007): fostering a more inclusive approach to research,, bringing the unique perspectives of consumers to decisions around planning and methodology, helping to form collaborative relationships between consumers and researchers, increasing the credibility of research, providing an opportunity for consumers to build research skills, and potentially increasing recruitment and retention of participants.

Barriers to consumers participating in research and program planning have also been identified. These include: mental health professionals not valuing consumer participation (Telford \& Faulkner, 2004; Griffiths, Jorm \& Christensen, 2004; Entwistle, Renfrew, Yearley, Forrester \& Lamont, 1998; Ochocka, Janzen \& Nelson, 2002); professional researchers’ discomfort with changing power dynamics (Telford \& Faulkner, 2004); research with consumers not being viewed as credible (Telford \& Faulkner, 2004); lack of consumer skills to do research (Goodare, \& Lockwood, 1999; Hanley, Truesdale, King, Elbourne, D. \& Chalmers, 2001); the need for consumer training in research roles (Goodare, \& Lockwood, 1999; Hanley, Truesdale, King, Elbourne, D. \& Chalmers, 2001); and the risk of participation being tokenistic (Telford \& Faulkner, 2004).

While the benefits and challenges of participation are clear, there is less clarity on tangible and effective methods for ensuring meaningful consumer participation in service delivery and research. This study was designed to address this gap, and is guided by the following principles : participatory processes (Nelson et al., 2004); democratic pluralism (Nelson et al., 2004; Fetterman, 1999), and respect for differences guiding evaluation (Fetterman, 1999); and providing research training to consumers (Nelson et al., 2004). 
The specific objectives of this study included: 1) to describe the implementation of the People with Lived Experience Caucus and barriers and facilitators to implementation; and 2) to investigate the factors that facilitated meaningful inclusion of Caucus representatives in research and service planning - from the perspectives of both Caucus members and project stakeholders.

\section{Background Information}

The At Home/Chez Soi Research Demonstration (“At Home”) project is a randomized controlled trial assessing the effectiveness of Housing First for homeless people with mental illness in five Canadian cities: Moncton, Montreal, Toronto, Winnipeg and Vancouver (Goering, Streiner, Adair et al., 2011). The overall goal of the "At Home" study is to generate evidence about what services and systems could best support homeless people with mental illness in Canada. The project provides housing and clinical services to over a thousand participants.

The Toronto Site of the At Home project commissioned a People with Lived Experience Caucus ("the Caucus") to support project implementation and advise all aspects of the project throughout its duration. Before project launch in November 2008, people with lived experience were engaged in consultative meetings with the Mental Health Commission of Canada (MHCC), to introduce the project to the community and obtain community input. Following project launch, consultants were hired to engage the larger consumer community in Toronto, and to set up a model for ongoing consumer inclusion in the Toronto Site. Focus groups, open to anyone who wished to participate, were held at eleven agencies serving consumers to determine their desired model of and potential barriers and facilitators of project participation. While several participation options were proposed, the model ultimately recommended and chosen was a consumer Caucus who would act as a project advisory body. This model of participation was 
chosen because it aligned with suggestions from the literature as well as themes from the focus groups (Action Consulting, 2009). Two consumers from each of the 11 focus groups were subsequently invited to join the Caucus: one representative chosen by the host agency, and one chosen by the focus group facilitators. While criteria for selection by the host agency are unknown, the criteria for selection by focus group facilitators included: eagerness to participate in the project and a desire to take leadership within the project, experience with similar initiatives in the past, and willingness to be involved in the Caucus for the duration of the project..

The Caucus was established formally in June 2009 with 22 members, and had been supporting the At Home project for nearly three years at the time of this study. Working for Change, an organization advocating for employment opportunities for consumers (formerly the Ontario Council of Alternative Businesses), was selected to provide trusteeship and coordination for the Caucus in May 2010. Caucus members had experience of a range of mental health problems and many had experienced or were currently experiencing homelessness. No diagnostic information or length of time homeless was requested from Caucus members, but all of them would have qualified for the study at one point in their lives. Some caucus members were already engaged in advocacy work, others had no prior experience in this area. There was representation on the Caucus of visible minorities, Aboriginal people and minority sexual orientations. At the time of the study, the demographic profile of the Caucus included four males, eight females, and one transgendered person as well as one person aged 18-30, ten people aged 31-64, and two people over 65 years of age.

The Caucus has held an extensive advisory role in the Toronto Site of the At Home project. At least two Caucus members sit on all project workgroups and Caucus members participate in additional internal Caucus sub-committees. The primary duties outlined in the 
Caucus protocol include: 1) sending consumer representatives to all project committees to provide advice from a consumer perspective and inform the successful direction of the project, 2) holding monthly Caucus meetings, and 3) documenting the process of formation for future consumer engagement efforts.

The study team for this project was composed of a member of the research team and three Caucus members who designed and carried out the study with the oversight of an advisory group of stakeholders. Three Caucus members were asked to be co-evaluators to ensure that principles of participatory process and inclusion were extended to this study.

\section{Method}

This study gathered data from Caucus members as well as frontline service providers, managers, and researchers about their experiences working with/in the Caucus, using qualitative methods including focus groups, interviews, and document review. The St. Michael's Hospital Research Ethics Board approved the study and participants provided written informed consent.

\section{Study Population}

Study participants included current members of the Caucus, as well as individuals working on the At Home project who had regular interaction with Caucus members. Regular interactions were defined as one or more interactions per month with the Caucus Coordinator or any Caucus members. All individuals who satisfied the inclusion criteria were invited to participate in the research study; this produced a potential sample of 13 Caucus members and 20 other project stakeholders. A total of 33 participants were invited to participate in the study.

\section{Data Collection}

This study used qualitative data collection methods, including: 
1) Document review. At total of 42 documents related to the Caucus were reviewed for the purpose of better understanding the Caucus history, formation, and communication. All Caucus members and project stakeholders were invited to submit relevant documents for review. Documents included: meeting minutes (nine documents); governance documents (11 documents); communication documents including updates, fact sheets, and internal and external memos (13 documents); semi-annual reports (six documents); and Caucus position papers (three documents). Each document was reviewed by two members of the study team: one researcher and one Caucus member.

2) Interviews and focus groups. All participants were given options to take part in either a focus group, individual interview, or provide an individual written response or audio-recorded response to the interview questions. Questions were developed collaboratively by the study team (including Caucus members) and were reviewed by the steering committee. Topics covered were based on the evaluation objectives above, and were provided to participants in advance. Interviews and focus groups were conducted by the researcher on the study team, as decided by consensus . Caucus members and stakeholders participated in separate focus groups. Each individual interview took between 30-60 minutes, while each focus group lasted between 60-120 minutes. All focus groups and interviews were audio-recorded, transcribed and coded. The same questions were asked in all individual interviews and focus groups with Caucus members and other stakeholders.

\section{Participation}

There were no refusals to participate among potential participants; however, no response was received from 10 individuals despite multiple follow-up attempts. A total of 23 people participated in the study. In total, six Caucus members participated in the individual interviews, 
four participated in a focus group, and one submitted a written response, for an overall Caucus participation rate of $85 \%$. Amongst staff, seven people participated in focus groups, four participated in individual interviews, and one submitted written answers to the questions, for an overall staff participation rate of $60 \%$. There were a total of 10 individual interviews, two staff focus groups: one with four participants and one with three participants, and one Caucus focus group with four participants. All individuals who participated in the study had been working on the At Home project for over a year.

\section{Data Analysis}

Once transcribed, interview and focus group data along with documents reviewed were analyzed using a grounded theory approach: employing inductive strategies and using comparative analysis to first develop categories to explain data, and subsequently identify patterns and relationships (Charmaz, 2003; Glaser \& Strauss, 1967). More specifically, open coding was used with a series of codes that were extracted from the text itself. These codes were developed by the study team who first went through transcripts individually (with at least two members reviewing each transcript) and then arrived at specific concepts and themes. The codes were then grouped into similar concepts in order to make them more manageable and coherent, and finally categories or themes were established to describe the story of the Caucus as it emerged from the data collected.

Documents submitted for review were analyzed by at least one researcher and one consumer using a common template created to collect information around key themes related to the study. Template themes included: milestones and expertise, workgroups, representation and voice, documented influence and change, Caucus development and history, sustainability of the 
Caucus, adaptation, implementation challenges, and implementation successes. The template had three columns for each theme requiring reviewers to extract information, interpret the significance of it, and synthesize it with other information. Each document had at least two templates created, which were reviewed for consistency. Where inconsistencies arose in the information captured and interpreted, a third study member was asked to review the document to reconcile the discrepancy. Concepts from the documents reviewed were similar to those arising from transcripts and were subsequently integrated with these findings to create the themes described in this paper. In several cases, the documents reviewed provided detailed information about the concepts that arose in the transcriptsas noted in the results section.

\section{Results}

There were four main themes arising from the study: model of participation and the role of the Caucus, challenges of inclusion, growth and development of the Caucus over time, and ingredients of successful engagement.

\section{Model of Participation and Role of the Caucus}

The majority of study participants $(\mathrm{n}=18,78 \%)$ described the Caucus as having an advisory role within the Toronto project, advising or consulting from the perspective of consumers. The Caucus was also regarded by some $(n=10,43 \%)$ as making the project more relevant to the needs of participants and the community, and helping project partners develop more empathy for At Home participants.

"For me from day one it's all been about ethics, and respect, and making sure this project did not go off the rails in the way they worked with the participants." 
Participants additionally saw the Caucus as giving opportunities and a home base to Caucus members. Some $(\mathrm{n}=14,17 \%)$ described the importance of Caucus members having their own place to meet and discuss issues.

Many participants ( $\mathrm{n}=10,43 \%)$ highlighted the lack of formal process for selecting Caucus members, and commented that those who attended MHCC information meetings and focus groups at various community agencies just "became" the Caucus. The documents reviewed provided clarity on the selection process, but revealed that the process was not well communicated to stakeholders. As some participants noted $(n=10,43 \%)$, this created confusion about what the model of participation was meant to be and who the individuals on the Caucus were representing. Challenges stemming from this model of participation will be discussed in the next section.

A recurrent theme regarding the role of the Caucus was related to the fact that most decisions regarding this national project were already made by the time the project was rolled out at the site level, and thus there was limited opportunity to give input at the national project level. This finding was confirmed in the document review. More information about the design of the multi-site project has been published elsewhere (Goering, Streiner, Adair et al., 2011).

"There was... admittedly I think a limited forum ... for the consumers to be influencing the way the service was delivered and the way the research was done." "And there should have been much more ... opportunities for people working on the project to come together with people who have lived experience to have conversations about the work in a much more broad way... that would then influence the way in which the people doing the work would approach doing the work, right."

\section{Key Challenges of Inclusion}


Major themes within challenges of inclusion were: resources and accommodations; meetings and interactions; and selection and representation.

Resources and Accommodations. Some participants $(n=4,17 \%)$ raised concerns about resource constraints and raised questions about the ability and willingness of Caucus members to contribute to the project without being paid.

"I mean from a community development standpoint... when you pay people for their labor, as opposed to asking people to volunteer it produces very different results and I think that has been embodied in this project... What it has meant is that people won't step outside of their rigid boxes... even asking people to do something, to think through something you give someone a document and ask them on their own time... to give feedback they won't do it. Because they want to be paid to do it. And we can't afford to pay people to do every single thing."

A few project stakeholders $(n=3,13 \%)$ also noted that some, but not as many, accommodations should be made for consumers in future projects, suggesting that the extent of accommodations made was creating a double standard of expectations of Caucus members and other project partners. Accommodations in this case refer to provisions such as: food being provided at all meetings, extra time being provided at meetings for discussion that were offtopic, all Caucus members travelling to conferences in pairs, and Caucus group team building and recreational activities that were funded by the project budget.

Yet on the other hand, other stakeholders $(n=6,26 \%)$ saw the need for project partners to make more accommodations for consumers. This theme also emerged in document review. As one stakeholder says, 
"To realize that chaos always happens... especially with people that are marginalized... so even though they're providing solutions to the project... they're still living that life... I wish people had been more lenient to understand that ... to be able to see that... I think that is still a challenge but not as much as before."

Meetings and Interactions. Many participants $(n=9,39 \%)$ discussed how disorganized and negative Caucus meetings can be. They pointed out that Caucus meetings require expert facilitation and a patience.. Documents reviewed noted conflict within meetings as a recurrent problem.

Participants $(n=8,35 \%)$ noted that tangential comments are allowed to take over project meetings, reinforcing negative views of consumers and stereotypes of people with mental illness. Others $(n=6,26 \%)$ spoke about meeting disruptions, and expressed that they did not know how to proceed with a meeting when a Caucus member "goes off on a tangent".

Data analysis also revealed a perceived lack of honest conversations about the Caucus, with some staff $(n=3,13 \%)$ citing the need to be overly sensitive around Caucus members and fear in interactions.

"I also think that in the absence of having honest conversations about the participation of Caucus members... everybody says it's a good thing... And yet you sit through meetings where people are clearly annoyed by the way in which Caucus members are engaging. And chairs don't know how to handle that ... ... the Caucus doesn't know how to handle that. We don't know how to handle that because nobody is actually identifying it as a problem." 
It was also noted by many $(n=8,35 \%)$ that it is of "no fault of the individual Caucus members" that these difficulties emerge, rather, they stem directly from the Caucus selection process, not requiring prior group experience or ability to tolerate differences of opinion. Participants $(n=8,35 \%)$ also highlighted disruptions in work group meetings and noted several problems stemming from these disruptions As one participant said:

"I have to say with the [workgroup] I have not felt that it was beneficial at this point... I feel like it's therapy to be honest and I feel like our group is not functioning... we're doing group therapy... and allowing people to talk, and managing their upsetness and the rolling of the eyes and teaching basic social skills."

On the other hand, some Caucus members $(n=15,22 \%)$ voiced that they weren't allowed to fully be themselves in meetings,. The following laconic quote embodies this theme:

"You told the truth, and then they shut you up because mental health is not a pretty picture, you cannot sanitize it, you have to tell the truth... Don't try to sanitize my truth." Others, both Caucus members and project stakeholders, felt that the project partners should have done more to support Caucus members to conform to workplace expectations. Caucus members $(n=6,26 \%)$ reported feeling sometimes, but not always, valued in workgroups. One Caucus member explains:

"I do feel that most of the time I am given ...equal chance to participate and that for the most part committee members... respect both me and my lived experiences... however... there have been occasions where I have been told that someone else in our group is "expert" in a topic ... and felt that my personal lived experiences and knowledge ... have been invalidated. 
Representation and Selection. Study participants brought up two problems with the representativeness of the Caucus. Firstly, they $(n=6,26 \%)$ felt that the Caucus was not representative of the "At Home" participants. Despite Caucus members closely resembling "At Home" participants demographically, they did not represent their direct concerns because there was intentional independence between the two groups.

"Even though we talk about it as giving people with lived experience a voice, which it is,

... they're not in any means representative of or selected by the participants in the study, which would probably be preferable if it were possible."

The second issue discussed $(\mathrm{n}=6,26 \%)$ was the Caucus not being representative of all consumers in Toronto, either because they were not elected or because the Caucus is polarized in ways that the larger consumer population is not. The only document commenting on this theme stated a different perspective, that Caucus members were believed to be representative of the larger consumer community. Still, one stakeholder noted:

"It was a self-select group that came from a very specific ... anti-psychiatry perspective... and this is not necessarily the representative sample of consumers." The most critically scrutinized element of Caucus participation was member selection. Nearly every participant cited challenges with Caucus member selection $(n=19,83 \%)$, describing problems with both the method and the outcomes of selection. The main difficulty identified with Caucus member selection was the lack of prior experience working in groups and qualifications beyond having lived experience of homelessness and mental illness. One participant described the selection as people being "volunteered" and characterized the process as a "default mechanism". . 
Many participants $(n=7,30 \%)$ voiced the concern that the way Caucus members were selected set them up to fail.

\section{Growth and Development}

Our findings revealed a tremendous amount of Caucus growth over time. Participants $(n=6,26 \%)$ described a difficult early period, a period of "growing pains", as one participant called it. During this time, there was fighting between Caucus members and reported incidents of sexism, racism, and disrespect as well as a "culture clash" between Caucus members and other project stakeholders.

"When they started with the lack of leadership... there was a lot of infighting that would come to my attention...people would come and say you know there are fights at our meetings... it's horrible, people call people names, people are bullying other people..."

A few participants interviewed pointed out that this period of turmoil was unavoidable because the Caucus brought together consumers who had never worked in groups before. Others $(\mathrm{n}=5,22 \%)$ described it as something that happened because people were still healing and dealing with their own issues. Some participants $(n=5,22 \%)$ directly attributed early Caucus difficulties to the way it was formed, and commented that time was needed for Caucus group development.

Many participants $(n=12,52 \%)$ pointed to the positive growth within the Caucus that was marked by clearer purpose and goals and by improvements in meetings over time. Both the initial turmoil and subsequent growth was evident in the document review templates as well. Factors that aided this development reportedly included: time; training sessions; and stakeholder, Working for Change, and Caucus Coordinator support. 
Participants $(\mathrm{n}=15,65 \%)$ also observed significant skill development over time by both individual members and the entire Caucus with lived experience turning from a source of shame to a source of pride and fuel for change for some.

"It has amazed me most how open and trusting Caucus members have become of one another and too of project members in general and how many members have moved from initial signs of showing shame from experiencing stigmas and stereotypes related to their lived experiences to now openly speaking about such from a point of power."

Several Caucus members $(n=7,30 \%)$ felt that project involvement gave them something positive to work on, and made them feel valued. Yet despite the development described above, some participants $(n=5,22 \%)$ noted that Caucus members are still developing, and still going through a process of healing.

\section{Successful Engagement}

Despite the challenges, individual and group growth a over time led to several positive contributions over the three years of Caucus participation. Study participants praised Caucus members for their persistence in identifying areas in need of improvement and advocating for change. Similarly, documents reviewed identified persistent advocacy on issues important to the Caucus.

Including the consumer perspective, in general, was seen as a great Caucus accomplishment. Many participants $(n=12,52 \%)$ noted the richness that the consumer perspective brought. Others commented that consumer inclusion set precedence for future projects: 
"I think the Caucus has made a difference in setting precedence/making an example of how to effectively involve People with Lived Experience ... into project planning and leadership work."

Both the documents and qualitative data $(n=19,82 \%)$ lauded the tangible differences the Caucus made to the Toronto project including: raising research honoraria for treatment-as-usual (TAU) participants; providing gift cards to participants for temporary supplies (i.e. air mattress) in the event of prolonged furniture delays; and getting media training for At Home participants being interviewed about the demonstration project.

Study participants also identified that Caucus members made a difference in the way they challenged projectassumptions. Both stakeholders and Caucus members talked about Caucus voices making a difference in either stakeholder's perspectives or actual decision making. Caucus members challenge of project assumptions was also evidenced in the documents reviewed. One stakeholder mentioned:

"It raises the level of the discussion and it keeps us honest around the statements that we make and all that stuff"

When talking about factors that supported individual Caucus member development, participants discussed the extensive training done by Working for Change and the support of the Caucus Coordinator. This training included sessions on leadership, teamwork, communication, story-telling, non-violent communication and monthly diversity training sessions.

"I think that the trustee has been ... the most significant catalyst to getting them to where they've gotten to, so far."

Study participants $(\mathrm{n}=12,52 \%)$ referred to the resources and opportunities that were provided to Caucus members, including honoraria, food, TTC tokens, computers, cell phones, 
internet bills, and phone bills - ensuring ful project participation. As one interviewees commented:

"The funding I think would be the number one thing because it ... I have this sense that a lot of people feel valued and respected... like their opinions and their expertise...matters because there has been so much money put in to this project and for the Caucus... specifically... and the self-esteem you gain."

Finally, study participants referenced the natural attrition of Caucus members that created a smaller group size as a success. The group size declining from 22 to 13 members was seen as a positive change that improved group functionality. This positive change was also prominent in the document review findings.

\section{Discussion}

Our findings highlight the complexities involved in including consumers in a large research demonstration project. There was rarely an instance where the themes and opinions expressed were attributable to one particular perspective or stakeholder role within the study. Many of the most critical comments about the Caucus came from Caucus members, while many of the most positive comments were expressed by other stakeholders. Furthermore, some issues, such as providing resources to Caucus members, were cited as a mechanism of successful inclusion and also as a challenge, underscoring the careful attention needed to each factor. More importantly, most of the views presented in this report were shared by Caucus members and project staff alike.

A key criticism of non Caucus stakeholders was that Caucus members were not representative of study participants, as there were not drawn from among the project's service recipients, and that they were not representative of consumers in Toronto. It is unclear how this 
perspective colored staff and Caucus member interactions, but it clearly diminished the perceived "legitimacy" of the Caucus, an important consideration in future efforts to engage consumers in service planning, delivery and research.

The emphasis that many study participants placed on Caucus formation and implications for Caucus function was also prominent. The finding that the selection model and type of representation chosen had a profound impact on Caucus functioning and the success of inclusion suggests that in future efforts to include consumers, significant forethought should be devoted to the planning process. There are other models of consumer participation, such as having consumers within workgroups, having a participant board, or consulting existing groups and networks on an ad hoc basis (Miller \& Moore; 2009), or adaptations of these models to suit a particular program and stage of intervention (Monson \& Thurley, 2011). Such models should also be considered by others approaching similar work. Using a different approach might have produced more favorable results or contributed to a less challenging period of implementation. .

The many successes and challenges identified can nevertheless inform future efforts for meaningful inclusion of consumers in similar settings. For groups considering a Caucus model of participation, lessons learned from this study can be summarized as follows:

1. Selection of participants should be purposeful, based on the skills required to perform specific tasks and should be communicated in advance. Direct service recipients should be included where possible.

2. Once a group is selected purposefully, they should be made clearly aware of their role and expectations.

3. A coordinating body to support engagement and meaningful inclusion and problem solving is invaluable. 
4. Early involvement in a project to maximize potential contribution and impact is essential.

5. Regular opportunities to discuss and facilitate the process of inclusion, from each partner's perspective, can be helpful.

Notably, the results described above do not include the perspectives of the eight individuals who left the Caucus, and we are unable to determine how their perspectives and experiences differ from those described in this paper.

\section{Conclusion}

Despite several identified challenges, the consumers Caucus model used at the Toronto site of the At Home project succeeded in facilitating individual and group growth and development over time, and meaningful impact on a complex intervention. Lessons learned could support future initiatives in planning consumer inclusion. Given the challenges encountered using the caucus model, alternative models of participation should be also be considered in similar initiatives. Overall, the genuine effort made for meaningful inclusion was appreciated by all project stakeholders. From one Caucus member's words:

"I'd just like to commend the MHCC and more specifically the Toronto site team for their consideration of Toronto's people with lived experience in planning for and setting aside funding to support the equitable inclusion of people with lived experience in the Toronto project effort." 


\section{References}

Action Consulting. (2009). Consultants report: Involving people with lived experience in the mental health commission of Canada Toronto demonstration project. Toronto: Action Consulting. June 26, 2009

Carling, P.J. (1995). Return to community: Building support systems for people with psychiatric disabilities. New York: The Guilford Press.

Charmaz, K. (2003). Grounded theory. Strategies of qualitative inquiry, 2, 249.

Church, K. (1996). Beyond "bad manners": The power relations of "consumer participation" in Ontario's community mental health system. Canadian Journal of Community Mental Health, 15 (2): 27-44.

Church, K. (1992). Moving over: A commentary on power sharing. Toronto: Psychiatric Survivor Leadership facilitation program.

Cohen, O. (2005). How do we recover? An analysis of psychiatric survivor oral histories. Journal of Humanistic Psychology, 45: 333-354.

Constantino, V. \& Nelson, G. (1995). Changing relationships between self health groups and mental health professionals: Shifting ideology and power. Canadian Journal of Community Mental Health, 14(2): 55-69. 
Entwistle, V.A., Renfrew, M.J., Yearley, S., Forrester, J., Lamont, T. (1998). Lay perspectives: Advantages for health research. British Medical Journal, 316: 463-466.

Fetterman, D.(1999). Reflections on empowerment evaluation: Learning from experience. The Canadian Journal of Program Evaluation, special issue, 5-37.

Glaser, B. G., \& Strauss, A. L. (1967). The discovery of grounded theory: Strategies for qualitative research. Aldine de Gruyter.

Goering, P.N., Streiner, D.L., Adair, C., Aubry, T., Barker, J., Distasio, J., Hwang, S., Komaroff, J., Latimer, E., Somers, J., Zabkiewicz, D.,M. (2001), The At Home/Chez Soi trial protocol: A pragmatic, multi-site, randomized controlled trial of a Housing First intervention for homeless individuals with mental illness in five Canadian cities. BMJ Open, 2011, 1: 1-18.

Goodare, H., Lockwood, S. (1999). Involving patients in clinical research inproves the research. British Medical Journal, 319: 1315-1318.

Griffiths, K.M., Jorm, A.F., Christensen, H. (2004). Academic consumer researchers: A bridge between consumers and researchers. Austrailian and New Zealand Journal of Psychiatry, 38: 191-196.

Hanley, B., Truesdale, A., King, A., Elbourne, D. \& Chalmers, I. (2001). Involving comsumers in designing, conducting and interpreting randomized control trials: questionnaire survey. British Medical Journal, 322: 519-523.

Happell, B., \& Roper, C. (2007). Consumer participation in mental health research: Articulating a model to guide practice. Australasian Psychiatry, 15 (3).

Lord, J. \& Church, K. (1998). Beyond partnership shock: Getting to "yes”, Living with "No". Canadian Journal of Rehabilitation, 12 (2): 113-121. 
Lord, J. \& Dufort, F. (1996). Introduction: Power and oppression in mental health. Canadian Journal of Community Mental Health, 15 (2), 5-11.

Miller, L.D. \& Moore, L.R. (2009).Developing statewide consumer networks. Psychiatric Services 60: 291-293.

Monson, K. \& Thurley, M. (2011). Consumer participation in youth mental health service. Early intervention in psychiatry 5(4):381-8 (Nov). 